\title{
Acoustic Velocity and Attenuation in Porous Rocks
}

\author{
Kenneth W. Winkler and William F. Murphy III
}

\section{INTRODUCTION}

The acoustic properties of most crustal rocks are dominated by microcracks, pores, and the fluids contained within them. Dry rocks have much lower elastic moduli than do any of the constituent minerals. They are acoustically much more non-linear (stress-dependent) than other common materials. Fluid-saturated rocks exhibit attenuation and velocity dispersion that is not observed in dry rocks. All of these effects, and others, have been ascribed to the complex nature of the crack/pore structure of rocks, and to the behavior of fluids occupying and flowing within the pore structure.

Our intention here is to provide a concise status report on the present state of knowledge of rock acoustics. Several excellent review volumes have been published $[12,19,59,80,84,88,92]$, and should be consulted for additional information. Our approach will be to present experimental results that illustrate specific aspects of rock acoustics, and show how theoretical models help us understand the observations. Several field applications will also be discussed. Since velocities in rock have been studied more extensively than has attenuation, some sections contain little or no reference to attenuation.

K. W. Winkler and W. F. Murphy III, Schlumberger-Doll Research, Old Quarry Road, Ridgefield, CT 06877-4108

Rock Physics and Phase Relations

A Handbook of Physical Constants AGU Reference Shelf 3

Copyright 1995 by the American Geophysical Union.

\section{POROSITY}

Acoustic well-logs are frequently used to estimate porosity, especially in clean, water-saturated sandstones. This is based on an observation made by Wyllie et al. [103] showing that in clay-free, water-saturated sandstones under high-confining pressure, compressionalwave slowness (1/velocity) has a strong linear correlation with porosity. They proposed the equation-

$\frac{1}{V_{p}}=\frac{\phi}{V_{t}}-\frac{1-\phi}{V_{m}}$

where $V_{P}$ is the compressional wave velocity in the rock, $\mathrm{V}_{\mathrm{f}}$ is the velocity in pore fluid, and $\mathrm{V}_{\mathrm{m}}$ is the velocity in the solid matrix. Equation (1) is known as the 'timeaverage' equation, because the total travel time is the average of the times that a hypothetical linear raypath would spend in the fluid and in the matrix. It is, however, a correlation and not a rigorous theoretical model. Figure 1 shows an example from Gregory [31] where Equation (1) is compared to a suite of sandstone data. Significant amounts of clay in the rock will lower the velocity from the time-average prediction and recent work has attempted to derive correlations to both porosity and clay content (see Section 3).

Attempts to derive the porosity of carbonates from the time-average equation often under-estimate the true porosity. The difference between the derived porosity and true porosity is often called 'secondary porosity'. It is generally believed that secondary porosity is located in rounded, vugular pores whose shape is rather noncompliant and so has a negligible effect on the measured velocity.

The effect of pore shape is very important. A small amount of porosity can have a large effect on velocities if 


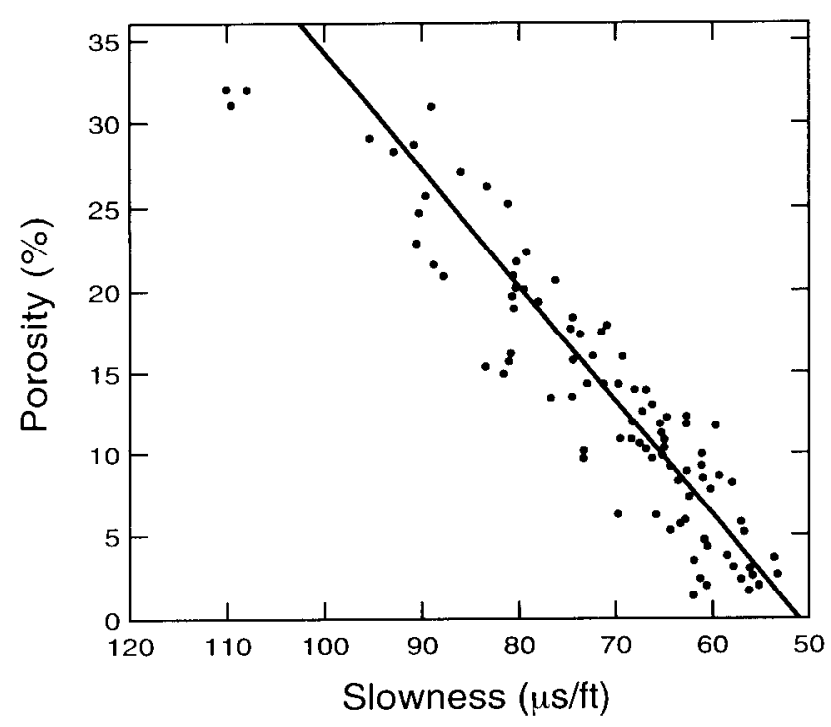

Fig. 1. Compressional wave slowness vs porosity data for water-saturated sandstones from Gregory [28], compared to time-average rclation (Equation (1)) for quartz-water system.

the porosity is contained in thin, flat cracks [86]. Such cracks are very compliant to stresses normal to the crack face. If the same amount of porosity is contained in spheroidal pores, it will have a minimal effect on velocity. Various models of velocities in rocks have been based upon distributions of pore aspect ratios [3, 18, 43] or upon generalized crack distribution parameters [60].

\section{MINERALOGY}

Mineralogy affects rock velocities in two ways. The most obvious is through the bulk and shear moduli of the solid matrix of the rock, which are primary inputs to all velocity models, whether crack-based or mixture models $[4,90]$. Indirectly, mineralogy controls the cementation and pore structure of the rock. Other parameters being equal, silica and carbonate cements produce higher velocities than clay cement. Carbonates, being more soluble, often have extremely complex pore structures which are not well described by conventional velocity nnodels.

Pickett [65] found a useful correlation between mineralogy and the ratio of compressional to shear velocities $\left(\mathrm{V}_{\mathrm{p}} / \mathrm{V}_{\mathrm{S}}\right)$ based on the data shown in Figure 2. The values in Table 1 were found to hold over a broad porosity range in consolidated rocks.

In more poorly consolidated rocks, the data tend to diverge from the trends shown in Figure 2, and many empirical attempts have been made to extend the correlations [14]. Several attempts have been made to estimate the effect of clay content on acoustic velocities $[15,32,42,82]$. These studies have generally found linear correlations relating velocity to both porosity and clay content. However, as with Pickett's results, great care must be taken when extrapolating these correlations beyond the range of sample properties used to derive them. As clay content increases, sandstones grade into shaly sands and shales. A transition occurs from a grainsupported framework with clay in the pore space, to a clay matrix with embedded, isolated grains. Our knowledge of the acoustic properties of shales is somewhat limited, primarily because they are difficult to work with in the lab. Most studies have emphasized the anisotropic nature of shales $[39,67,85]$, discussed further in Section 4.2. Velocities in shales are slowest in the direction perpendicular to bedding.

\section{STRESS EFFECTS}

The complex microstructures of most rocks cause velocities and attenuation to be very sensitive to stress. Increasing confining pressure or decreasing pore pressure cause velocities to increase and attenuation to decrease. Two points of view are useful, depending on the microstructure of a particular rock. Focusing on the pore

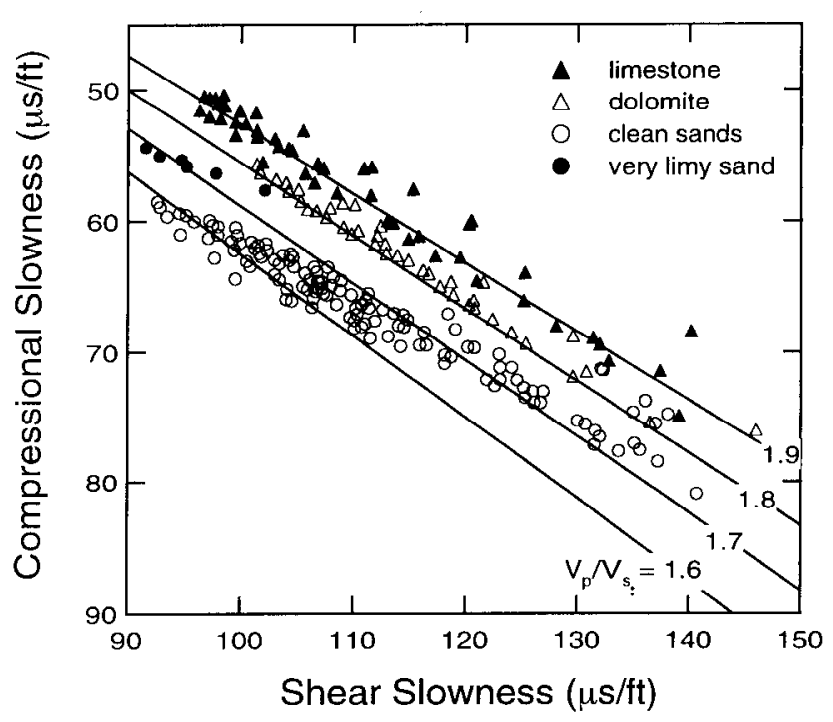

Fig. 2. Compressional wave and shear wave slowness data for several rock types from Pickett [61]. Lines are labeled with $\mathrm{Vp} / \mathrm{Vs}$ ratios. 
TABLE $1 . V_{P} / V_{S}$ vs Lithology

\begin{tabular}{cc}
\hline lithology & $\mathrm{V}_{\mathrm{p}} / \mathrm{V}_{\mathrm{S}}$ \\
\hline limestone & 1.9 \\
dolomite & 1.8 \\
clean sandstones & $1.6-1.7$ \\
\hline
\end{tabular}

space, we can imagine that very compliant pores (such as thin cracks) will close under small stresses. Increasing stress will close more and more pores, thereby stiffening the overall frame of the rock. Several theoretical models $[18,47,60,86]$ have utilized this approach. If instead we focus on the grain space, we envision isolated grains pressed together at their contacts. As stress increases, the grain contacts become stiffer, as does the entire frame $[8$, $9,24,41,54,55,83]$.

\subsection{Effective Stress.}

When applied to acoustic properties, effective stress is the difference between confining pressure and pore pressure [57]. Imagine a piece of rock totally enclosed by an impermeable jacket. If the rock is immersed in fluid which is pressurized, the fluid pressure will be transmitted through the jacket to the frame of the rock. This pressure is referred to as the external confining pressure. Now imagine that we can independently control the pressure of fluid in the connected pore space of the rock. This pore pressure acts to oppose the confining pressure. The pore pressure pushes on the inside surface of the jacket; the confining pressure pushes on the outside. Wyllie et al [104] showed very clearly that, to first order, velocities are a function of the effective stress on the rock (confining pressure minus pore pressure). Their data are reproduced in Figure 3. Note that the velocity is independent of confining pressure when the effective stress is held constant (by increasing pore pressure at the same rate as confining pressure). It is generally assumed that attenuation has a similar dependence on effective stress, though we are not aware of such a clear demonstration. Winkler and Nur [100] showed that increasing confining pressure, or decreasing pore pressure, both reduce attenuation in water-saturated rock (see Section 6.4).

\subsection{Anisotropy}

Anisotropic stresses cause velocities in rock to vary with direction $[10,45,58,72]$. An example of this effect is shown in Figure 4 from Nur and Simmons [58]. In this experiment, a granite sample was subjected to uniaxial stress, and velocities were measured as a function of azimuth, defined as the angle between the raypath and the uniaxial stress direction. At zero stress, the velocity is virtually independent of azimuth. As stress increases, a strong anisotropy develops. P and SH waves are much more sensitive to stress when propagating parallel to the stress direction than when propagating perpendicular to the stress direction. Nur [56] showed how this data could be modeled by assuming an initially isotropic distribution of cracks in the rock, and allowing cracks to preferentially close depending on how closely their normals are aligned with the uniaxial stress axis. It is likely that stress anisotropy will also create attenuation anisotropy, but no experimental data are available to confirm this.

A more extreme example is shown in Figure 5 for Berea sandstone. These data were taken on a dry cylinder subjected to uniaxial stress. Compressional wave velocities were measured both parallel and perpendicular to the stress axis. Shear wave velocities were measured perpendicular to the stress axis, but with polarizations both parallel and perpendicular to the stress axis. Shearwave splitting on the order of $20 \%$ is observed. Compressional velocities can differ by $50 \%$. As the rock approaches failure at $44 \mathrm{MPa}$, velocities begin to decrease. This is caused by dilatancy, the opening of

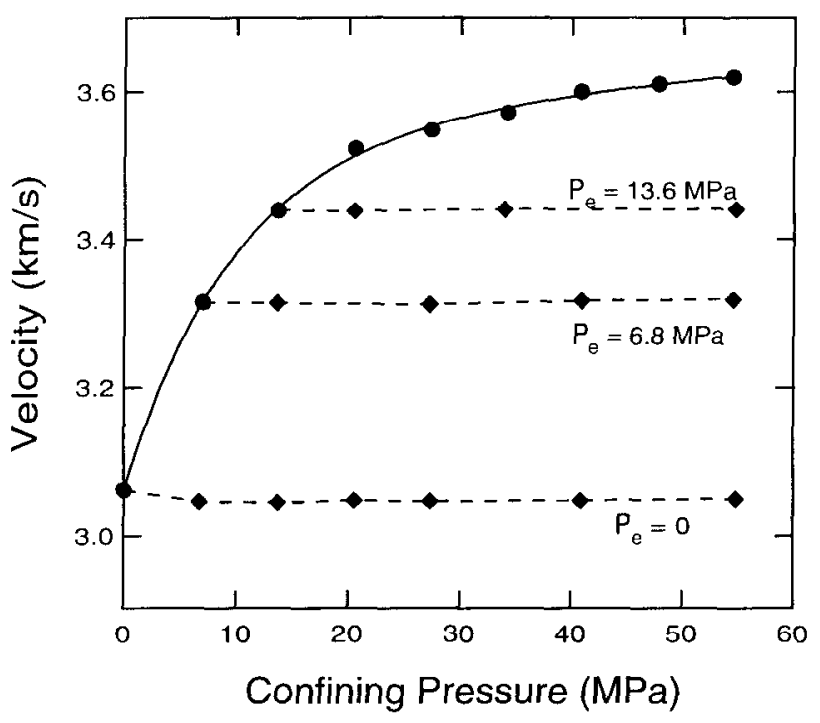

Fig. 3. Compressional wave velocity vs external confining pressure for water-saturated Berea sandstone from Wyllie et al. [99]. Solid curve has zero pore pressure, so effective pressure ( $\mathrm{Pe}$ ) equals confining pressure. On dashed curves, pore pressure increases with confining pressure to maintain a constant value of effective pressure. 
microcracks with normals perpendicular to the uniaxial stress direction $[11,45]$.

Many rocks exhibit velocity anisotropy even under isotropic stress conditions $[8,9,41]$. This is generally caused by preferential alignment of minerals or cracks. Shales in particular are often very anisotropic due to alignment of platy clay minerals $[39,44,6768,85]$. Rai and Hanson [68] found shear wave anisotropy of $~ 39 \%$ in a shale. In a field study, White et al. [94] observed $\sim 12 \%$ anisotropy in the Pierre shale. Theoretical models of

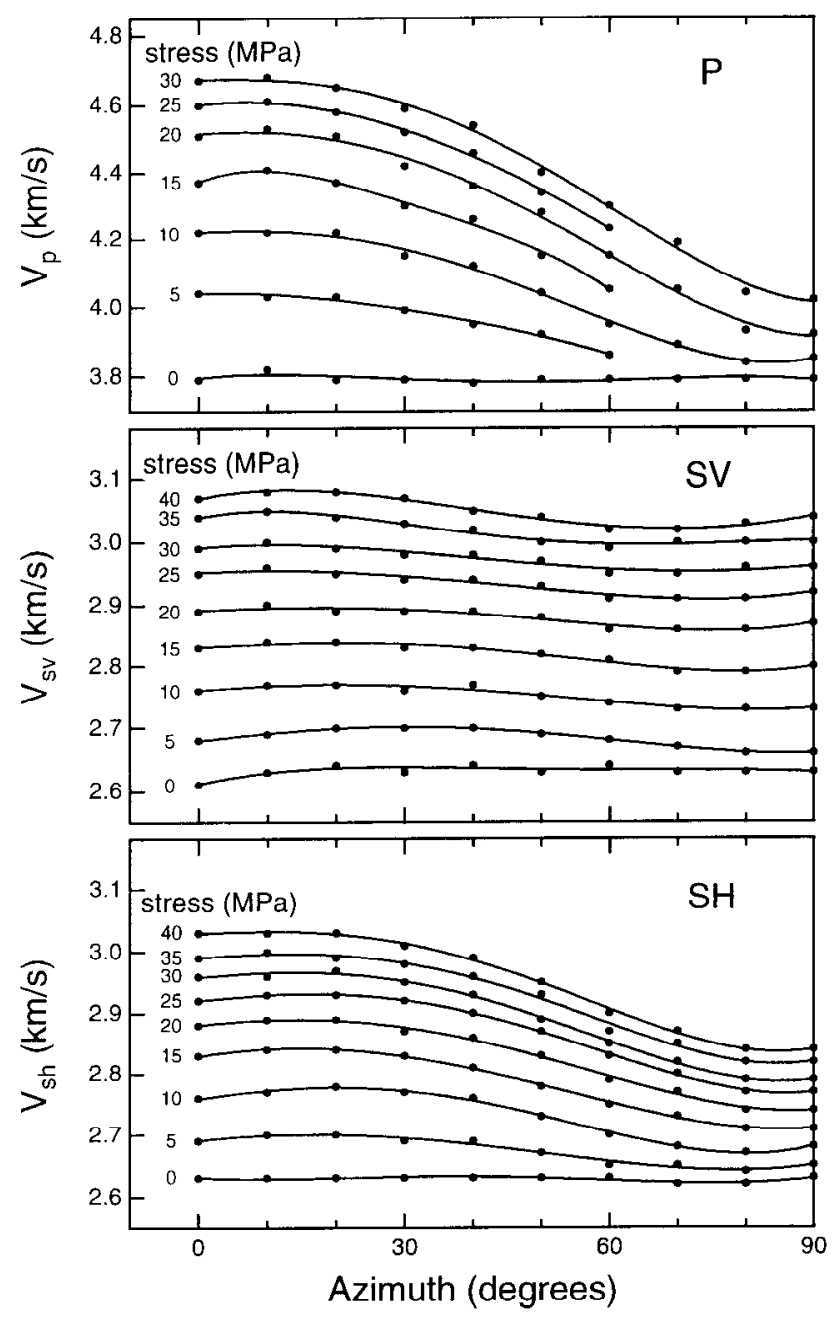

Fig. 4. Velocities vs azimuth in Barre granite under uniaxial stress from Nur and Simmons [55]. Azimuth is the angle between the uniaxial stress direction and the direction of wave propagation. $\mathbf{P}$ - compressional waves. $\mathrm{SH}$ - shear waves whose polarization direction is always perpendicular to the uniaxial stress direction. SV - shear waves polarized perpendicular to the SH polarization direction.

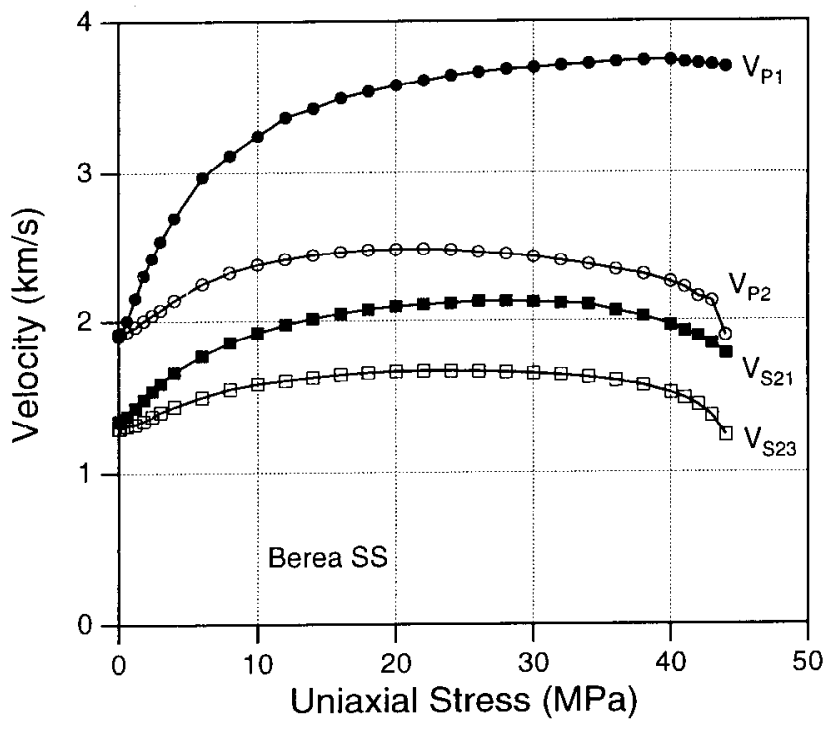

Fig. 5. Compressional and shear wave velocities in dry Berea sandstone as functions of uniaxial stress. $\mathrm{V}_{\mathrm{p} 1}$ propagates parallel to uniaxial stress direction. $\mathrm{V}_{\mathrm{P} 2}$ propagates perpendicular to uniaxial stress direction. $V_{\mathrm{S} 21}$ - propagates perpendicular to uniaxial stress direction and polarized parallel to stress direction. $\mathrm{V}_{\mathrm{S} 23}$ - propagates perpendicular to uniaxial stress direction and polarized perpendicular to stress direction. Very strong stressinduced velocity anisotropy and shear-wave splitting is observed.

velocity anisotropy in rocks are generally based upon aligned microcracks $[23,34,56]$. Thomsen [77] showed that an assumption of weak anisotropy (appropriate for many rocks) results in significant simplification of the governing equations.

\subsection{Nonlinear Acoustics}

Stress-dependent velocities are part of the more general field of nonlinear acoustics. 'Stress-dependent' refers either to externally applied stress or to the stressamplitude of the wave itself. Nonlinear acoustics is a well-developed field when applied to liquids or simple solids, such as plastics and metals. In addition to the bulk and shear moduli used in linear elastic theory, higherorder terms called third-order elastic constants are used. Isotropic solids will have three third-order constants; anisotropic solids will have many more. In addition to predicting velocity varying with external stress, nonlinear theory also predicts phenomenon such as harmonic generation and beam-mixing. Only recently have these later effects been demonstrated in rocks using smallamplitude propagating waves $[36,37]$. 


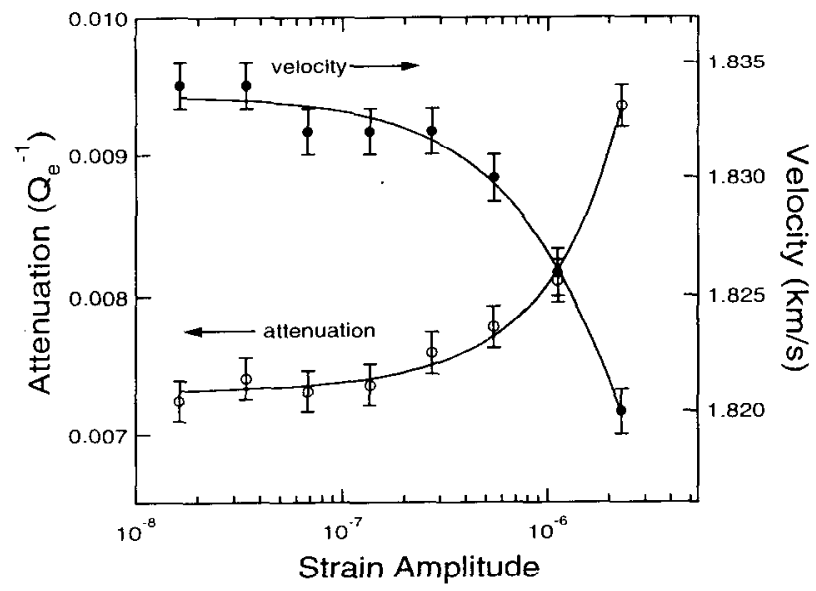

Fig. 6. Extensional wave velocity and attenuation data for dry Massilon sandstone vs strain amplitude from Winkler et al. [97].

Acoustic nonlinearity is readily observed using largeamplitude stress waves. Various studies, usually using resonant bar techniques, have shown that velocity decreases and attenuation increases when maximum strains exceed approximately $10^{-6}$. Figure 6 shows data from Winkler et al. [102] that demonstrates both effects. This amplitude dependence of velocities is a dominant cause of the difference between 'static' and 'dynamic' moduli. Static moduli are generally derived from direct measures of stress and strain, with strains exceeding $10^{-6}$. Dynamic moduli are measured from propagating acoustic waves with strains generally much less than $10^{-6}$. At low effective stresses, it is often observed that dynamic moduli are larger than static moduli [74]. The words 'static' and 'dynamic' imply a frequency dependence which does not exist in dry rocks (see Section 6.1). Cook and Hodgson [22] showed that static moduli vary with the size of the stress cycle used to measure them, with smaller stress cycles yielding larger moduli.

\section{FLUID EFFECTS IN LOW-FREQUENCY LIMIT}

As will be discussed below, fluid-solid interactions in rock can produce significant frequency dependence in both velocity and attenuation. For water-saturated rocks, the frequency dependence appears to he minimal helow about $1000 \mathrm{~Hz}$, but for oil-saturated rocks the frequency dependence may persist to much lower frequencies, scaling with the product of frequency times viscosity. In the low-frequency limit, fluid and solid motions are in phase.
In this limit, equations derived by Gassmann [28] allow us to compute elastic moduli of fluid saturated rock knowing the properties of both the dry frame and the 1luid. Gassmann's equations are also the low-frequency limit of Biot theory [5], a more comprehensive theory discussed below. Gassmann's equations require the bulk modulus of the matrix material $\left(\mathrm{K}_{\mathrm{S}}\right)$, the bulk modulus of the pore fluid $\left(\mathrm{K}_{\mathrm{f}}\right)$, the bulk modulus of the dry frame $\left(\mathrm{K}_{\mathrm{b}}\right)$, the shear modulus of the dry frame $\left(\mathrm{N}_{\mathrm{b}}\right)$ and the porosity $(\phi)$. K and $\mathrm{N}$ are the bulk and shear moduli of the saturated rock.

$$
\mathrm{K}=\mathrm{K}_{\mathrm{b}}+\frac{\left(\mathrm{K}_{\mathrm{s}}-\mathrm{K}_{\mathrm{b}}\right)^{2}}{\mathrm{~K}_{\mathrm{s}}\left(1-\phi-\frac{\mathrm{K}_{\mathrm{b}}}{\mathrm{K}_{\mathrm{s}}}+\phi \frac{\mathrm{K}_{\mathrm{s}}}{\mathrm{K}_{\mathrm{f}}}\right)}
$$

$\mathrm{N}=\mathrm{N}_{\mathrm{b}}$

Note that the shear modulus of the rock is the same dry or saturated, so the only effect pore fluids have on shear velocity is through increasing the density. The bulk modulus of the rock is increased by the addition of pore fluid, which essentially stiffens the pores with respect to compression. The bulk modulus of hydrocarbon pore

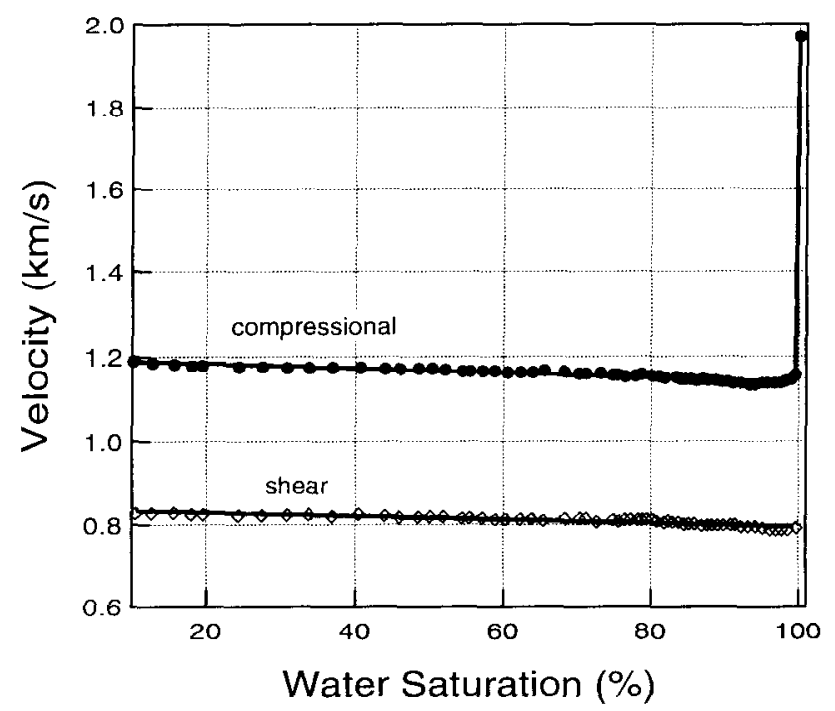

Fig. 7. Compressional wave and shear wave velocities in Massilon sandstone as a function of water saturation from Murphy [48]. Data were taken below $700 \mathrm{~Hz}$. BiotGassmann predictions fit data very well. Data corresponds to attenuation data in Figure 12. 

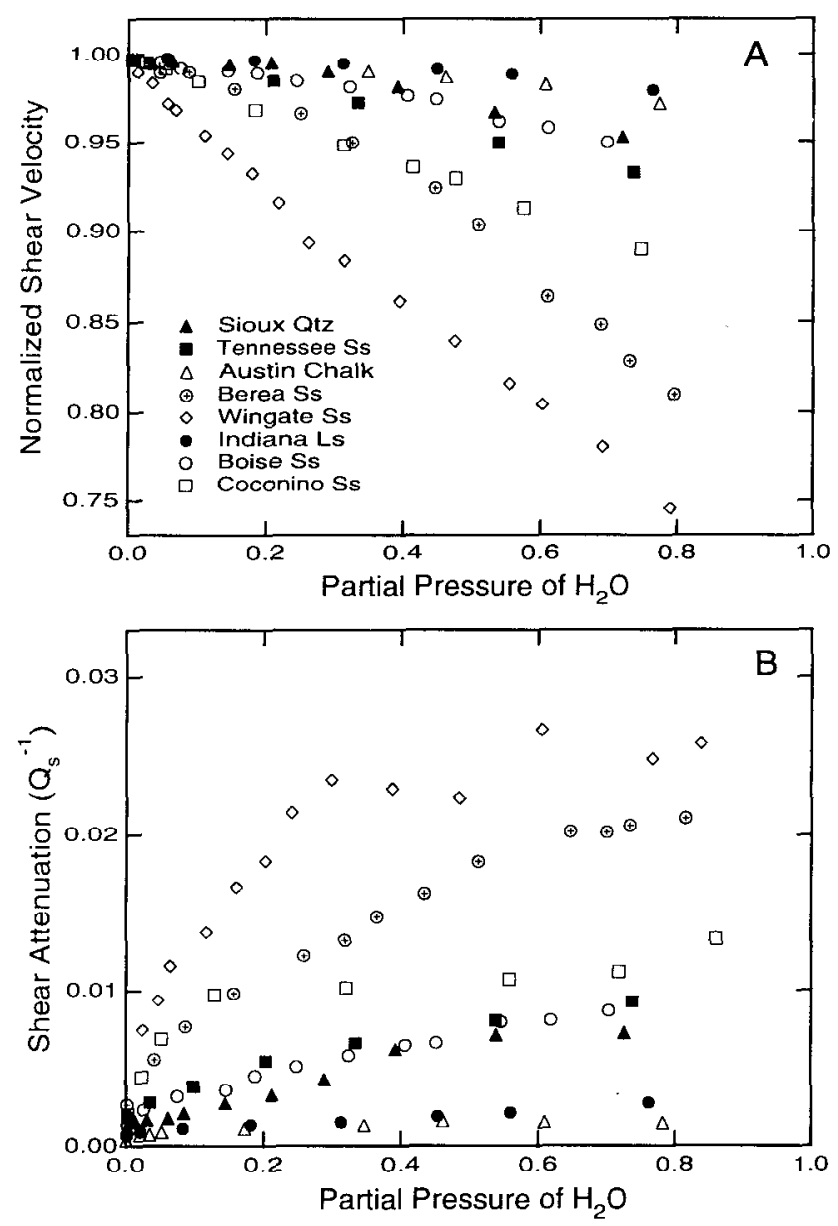

Fig. 8. Shear wave velocity (normalized) and attenuation data as functions of partial pressure of water vapor for several rocks from Clark et al. [18]. Water vapor decreases velocity and increases attenuation in nominally 'dry' rocks.

fluids can vary significantly with pressure, temperature, and composition [20,89]. When the pore fluid is a mixture of liquid and gas, then an effective fluid bulk modulus can be input to equation (2). Figure 7 shows data taken by Murphy [51] at $\sim 1 \mathrm{kHz}$, along with velocities calculated using Gassmann's equation. As saturation increases, $V_{P}$ and $V_{S}$ decrease up to very high saturations due to increasing density. As gas is eliminated at the highest saturations, there is a rapid increase in the fluid bulk modulus which causes both $\mathrm{K}$ and $\mathrm{V}_{\mathrm{P}}$ to increase. Figure 7 shows that the $V_{\mathrm{P}} / \mathrm{V}_{\mathrm{S}}$ ratio can be used as a gas indicator, but it is insensitive to the amount of gas in the rock. The gas effect on $V_{P}$ sometimes produces 'bright spots' on reflection seismograms, and has been used as a direct hydrocarbon indicator (discussed more fully in Section 7).
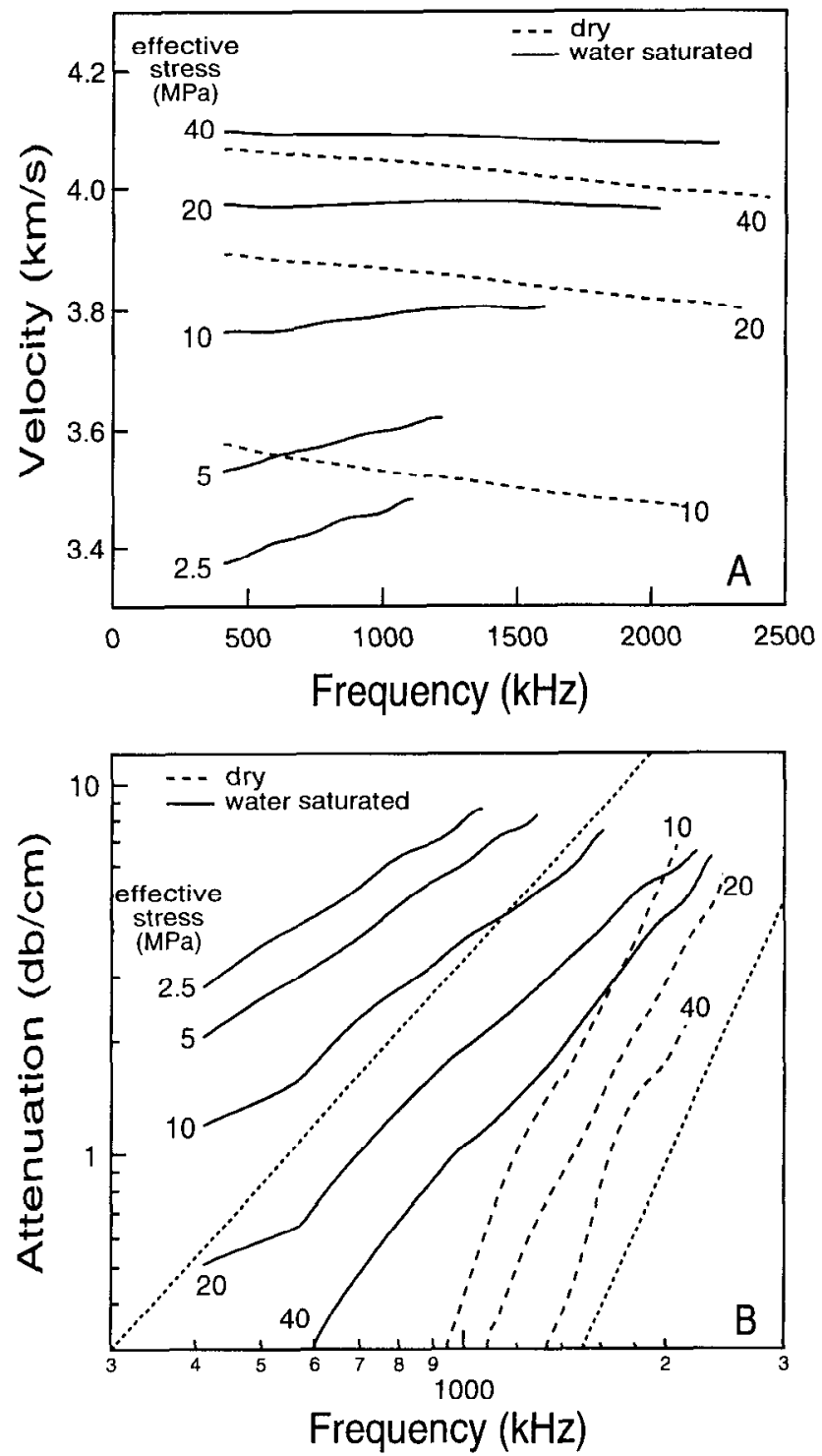

Fig. 9. Phase velocity (A) and attenuation (B) vs frequency in Berea sandstone from Winkler [91]. Dashed lines - dry rock. Solid lines - water saturated rock. Effective stress is indicated on the plots. On B, dotted reference lines having slopes of 2 and 4 are also plotted. Scattering theory predicts slopes of four on a log-log plot of attenuation $(\mathrm{db} / \mathrm{cm})$ vs frequency, and predicts velocity decreasing with increasing frequency.

One problem with applying Gassmann's equations is that the dry frame moduli, $\mathrm{K}_{\mathrm{b}}$ and $\mathrm{N}_{\mathrm{b}}$, are not easily determined, even in the laboratory. This is because both moduli are very sensitive to chemical interactions between the pore fluid and the frame. Rocks dried with heat and high vacuum have relatively high velocities and 

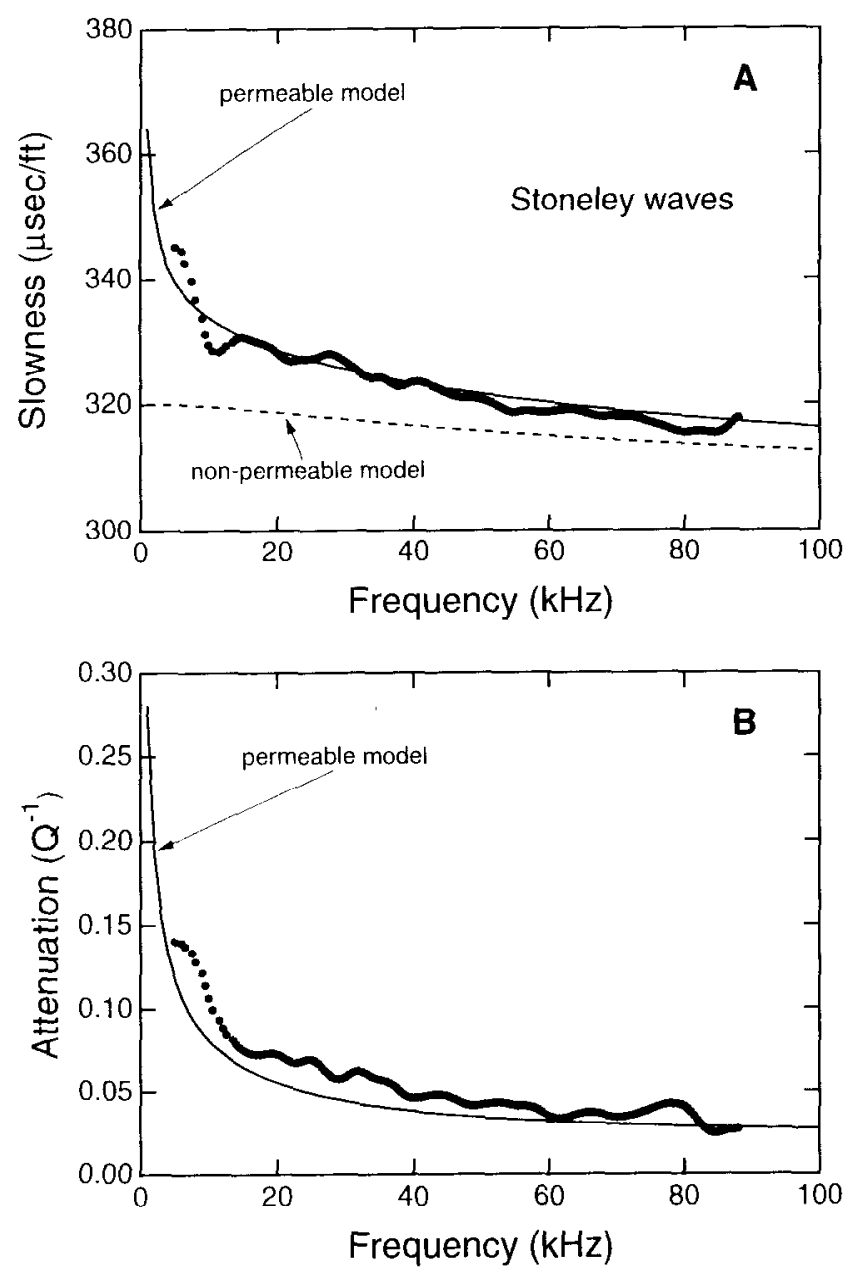

Fig. 10. Stoneley wave slowness and attenuation vs frequency in Berea sandstone measured in the laboratory by Winkler et al. [94]. Solid lines are model predictions (not fits) which include rock permeability. Dashed line indicates predicted slowness for non-permeable rock. Negligible attenuation is predicted in non-permeable rock. Permeability enhances both slowness and attenuation at low frequencies.

virtually no attenuation [78]. As monolayers of liquid are deposited on the internal surface of rock, velocity decreases and attenuation increases. Representative data from Clark et al. [21] are shown in Figure 8, where attenuation and normalized velocity are plotted as functions of water partial pressure. These data have been modeled [54, 83] as fluid monolayers lowering the surface energy of the grains and thereby reducing the cohesion and stiffness of the grain contacts. From a practical point of view, it is necessary to use $\mathrm{K}_{\mathrm{b}}$ and $\mathrm{N}_{\mathrm{b}}$ for the wettedframe in Gassmann's equations so that the chemical effects are incorporated into the frame moduli. This is often done simply by avoiding extreme efforts to dry the rock in the lab, assuming that 'room-dry' rocks have a water-wet frame. However, care must be taken if precise theoretical predictions are planned.

A recent application of Gassmann's equation by Murphy et al. [53] inverts Equation (2) to solve for the fluid bulk modulus, $K_{f}$, in terms of $V_{P}$ and $V_{S}$ measured in saturated rocks. To do this, they must assume a ratio of $\mathrm{K}_{\mathrm{b}} / \mathrm{N}_{\mathrm{b}}$ in dry sandstone, which they take to be 0.9 . They show that in high-porosity sandstones, the calculated value of $K_{f}$ has sufficient resolution to distinguish between gas, oil and water. A field example is discussed in Section 7.

\section{ATTENUATION/DISPERSION MECHANISMS}

Several mechanisms have been identified that contribute to attenuation and velocity dispersion of acoustic waves (dispersion being the frequency dependence). Each mechanism can dominate under certain experimental conditions of frequency, saturation and strain amplitude. It appears that under typical conditions in the earth's crust, in homogeneous rocks, attenuation and dispersion are dominated by viscous fluid/solid interactions. In heterogeneous rocks, scattering can cause significant dispersion and loss (not absorption) of energy, but we will only discuss this mechanism as it pertains to grain/pore scale heterogeneities. Attenuation and dispersion are physically related, one implying the other. Bourbié et al. [12] provide an extensive discussion of this relationship. For most mechanisms, attenuation varies with frequency. Frequencies having high attenuation also have the greatest dispersion. Attenuation is generally presented as either Q or $\alpha$, defined by [80]

$\frac{1}{Q}=\frac{M_{i}}{M_{r}}=\frac{\alpha V}{\pi f}$

where $M_{j}$ and $M_{r}$ refer to the real and imaginary parts of an elastic modulus, $v$ is the velocity of a wave controlled by modulus $M$, and $f$ is frequency.

\subsection{Friction}

For many years, frictional sliding between grains was considered a dominant mechanism of attenuation in rocks. In addition to its intuitive simplicity, friction predicts attenuation independent of frequency (constant $Q$ ) and no velocity dispersion. This was consistent with some early experimental data on dry rocks [64], and with data on 
saturated rocks over limited frequency bands [38]. It was also consistent with the cusped nature of stress-strain loops measured in low-frequency experiments, implying a non-linear mechanism [30, 49]. More recent work, however, has shown that attenuation can have significant frequency dependence, with corresponding velocity dispersion. The frictional mechanism is now associated with amplitude dependent velocity and attenuation (Figure 6) that is only important at large strain amplitudes [46, 70, 102]. At atmospheric pressures, strains $>10^{-6}$ are generally required to observe amplitude dependence. At larger effective stresses, even larger strains are needed [102]. The frictional mechanism probably is most important in the near field of seismic sources such as explosions and earthquakes.

\subsection{Scattering}

Acoustic scattering occurs whenever velocity or density heterogeneities occur on the same length scale as the acoustic wavelength. Although the scattered energy is not absorbed by the rock as heat, it does result in energy loss to the primary acoustic pulse. Scattering also reduccs the velocity of the primary pulse, causing velocity to decrease as frequency incrcascs. Most scattering models are designed for systems of weak scatterers, and so have not been successful in quantitatively predicting scattering in rocks. Sayers [71] presented a model predicting attenuation $(\alpha)$ increasing with the fourth power of frequency and velocity decreasing with the second power of frequency.

Winkler [96] presented experimental results showing scattering effects in sandstones at ultrasonic frequencies, where the scatterers are the grains and pores of the rock. Figure 9 shows velocity and attenuation data for Berea sandstone as functions of both frequency and effective stress. The attenuation data are plotted on a log-log scale for easy estimation of the slope. In dry rock, attenuation is well-fit by a fourth-power frequency dependence, and velocity decreases with increasing frequency, both in agreement with theory. In water-saturated rock, these effects are not so clearly observed because of the addition of fluid-flow effects (discussed below). However, at high effective stresses, fluid-flow effects are minimized and the data approach the trends expected for a scattering mechanism.

\subsection{Macroscopic Flow (Biot)}

Biot $[5,6]$ developed a theory of wave propagation in fluid saturated porous media that focuses on macroscopic fluid-flow. Various applications of Biot theory to porous media have been discussed by Johnson [35]. Biot theory
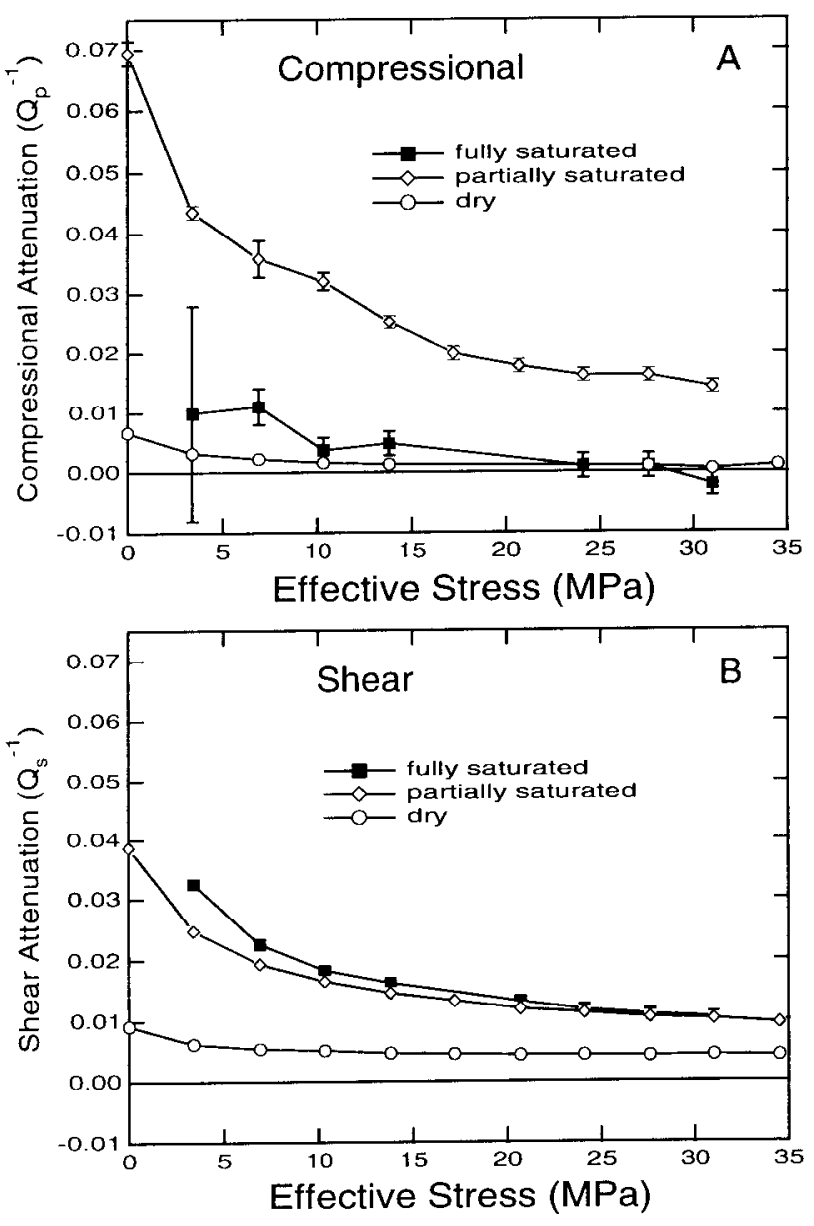

Fig. 11. Compressional and shear wave attenuation vs effective stress in Massilon sandstone from Winkler and Nur [95]. Data taken at frequencics ncar $1 \mathrm{kHz}$. Data are shown for dry, partially water-saturated $(\sim 95 \%)$ and fully water-saturated rock. Data are from resonant bar experiment, so compressional data was calculated from torsional and extensional data, resulting in larger error bars.

shows that acoustic waves create relative motion between the fluid and the solid frame due to inertial effects. As the matrix is accelerated, the fluid lags behind, resulting in viscous dissipation of acoustic energy. At low frequencies, the viscous skin depth is much larger than the pore size and fluid and solid are virtually locked together, moving in phase. Velocity is minimum and there is little attenuation. At high frequencies, the viscous skin depth is very small and the fluid and solid are essentially decoupled. Velocity is a maximum, and attenuation is low. For water-saturated rocks, the critical frequency in the 


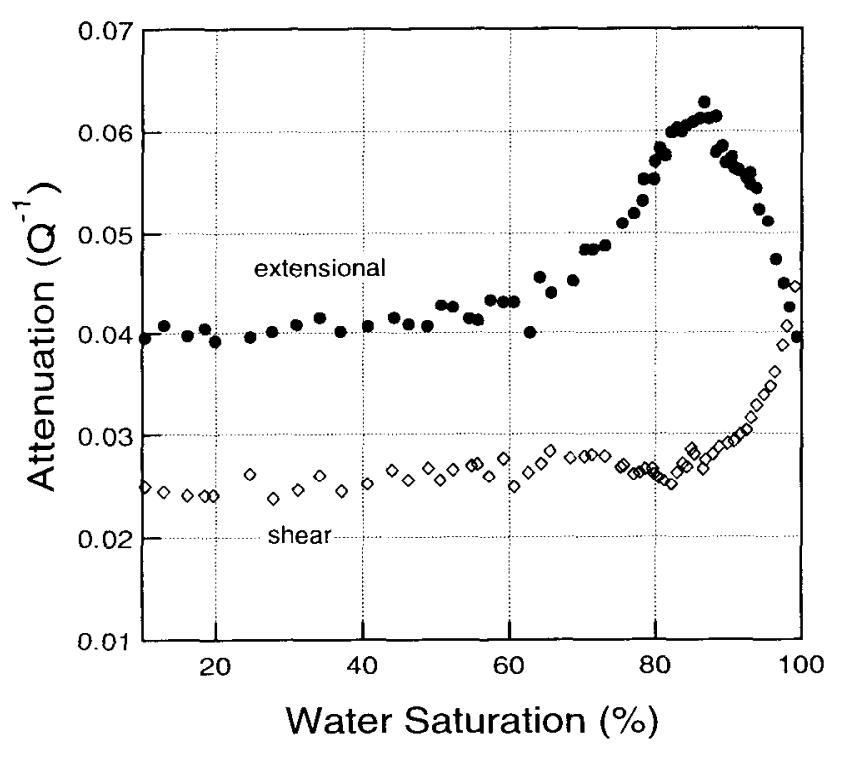

Fig. 12. Extensional wave and shear wave attenuation in Massilon sandstone as a function of water saturation from Murphy [48]. Data were taken below $700 \mathrm{~Hz}$. Data corresponds to attenuation data in Figure 7. Extensional (and compressional) attenuation is maximum in partially saturated rock. Shear attenuation is maximum in fully saturated rock.

Biot theory, where attenuation and dispersion are maximum, is often on the order of $100 \mathrm{kHz}$. Increasing viscosity pushes the critical frequency even higher. Therefore seismic waves and sonic logging are almost always in the low-frequency range of Biot theory. The low-frequency limit of Biot theory gives Gassmann's equations, discussed above.

For typical sandstones, Biot theory predicts a maximum of one to two percent velocity dispersion between its low- and high-frequency limits [97]. Predicted attenuation is also rather small, with minimum Q's on the order of 100. As will be seen, many rocks show much more dispersion and attenuation than this. An interesting prediction of Biot theory is the existence of a second compressional wave dominated by the properties of the pore fluid (often called the Biot slow wave). At low frequencies this wave is diffusive and at high frequencies it is propagatory. The propagating wave is very difficult to observe in rocks, though it has been seen in synthetic materials [66].

The diffusive mode of the slow wave is of practical importance for permeability estimation using borehole Stoneley waves. The Stoneley wave is a guided mode propagating primarily in the borehole fluid and applying pressure against the borehole wall. This pressure generates a diffusive wave in the pore fluid in the rock. Modeling has shown that this energy conversion from Stoneley wave to diffusive wave causes both attenuation and increased slowness of the Stoneley wave $[16,17,69$, 91]. These models were experimentally confirmed by Winkler et al. [99]. Their data for both slowness and attenuation vs frequency in Berea sandstone are shown in Figure 10, along with model predictions. In practice, it is possible to invert Stoneley slowness and/or attenuation measurements to estimate the permeability of rock formations [33].

\subsection{Local-Flow}

The Biot theory (discussed above) is concerned with macroscopic fluid-flow controlled by the permeability of the rock. Another fluid-flow absorption/dispersion mechanism, often called 'local-flow', is based upon microscopic fluid motion which is not coherent over macroscopic length scales. The pore space of a rock is generally very heterogeneous, some regions being very compliant while others are very stiff. This can result in fluid being squeezed out of grain contacts into nearby pores, or squeezed between adjacent cracks having different orientations with respect to a passing stress wave. This model has been addressed theoretically by many authors $[7,48,55,61,63,83]$. While most of these models can be fit to experimental data, none of them yet have the predictive power of the Biot theory. This is

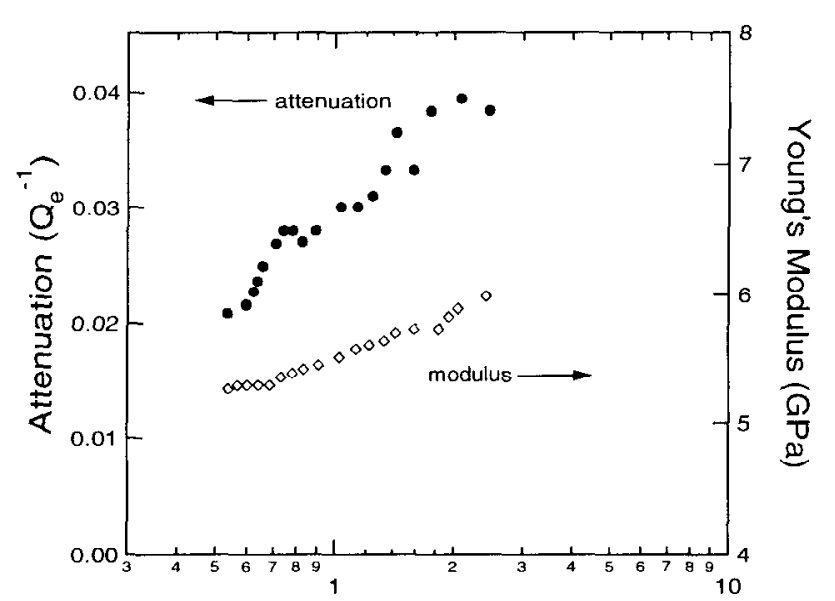

Frequency $\times$ Dynamic Viscosity $(\mathrm{kHz} \times \mathrm{cp})$

Fig. 13. Extensional attenuation and modulus vs product of frequency and viscosity, from Jones and Nur [37]. For one centipoise water-saturated rock, the horizontal axis becomes a $\mathrm{kHz}$ scale. Rock is Berea sandstone with 10 $\mathrm{MPa}$ confining pressure and 4.5 MPa pore pressure. 


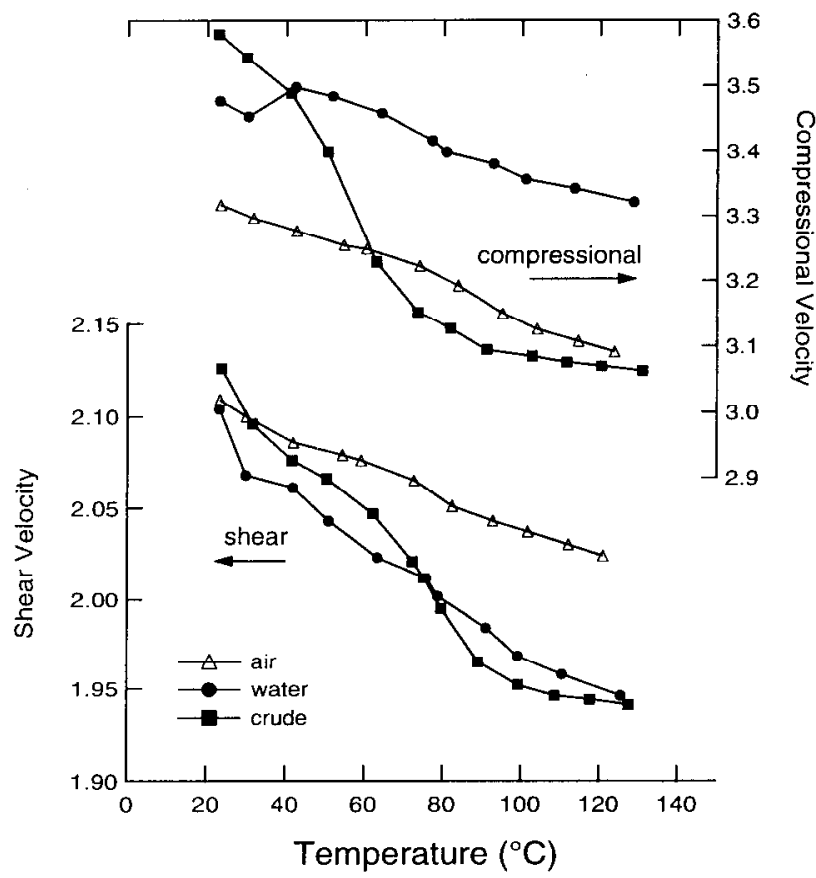

Fig. 14. Compressional and shear velocities in Boise sandstone as functions of temperature, from Wang and Nur [82]. Rock is saturated with air (dry), water, or crude oil. Effective stress is $15 \mathrm{MPa}$.

because they are all highly dependent on details of the microstructure that cannot yet be adequately quantified.

Nevertheless, many experimental results have been interpreted in terms of the local-flow mechanism [25, 41, $50,51,52,75,79,87,96,97,98,100,101]$. These experiments have addressed effects of saturation, stress, temperature, viscosity and frequency. Winkler and Nur [100] showed (Figure 11) that shear wave attenuation increases monotonically with saturation, while compressional wave attenuation is greater in partially saturated rock than in fully saturated rock. More detailed data taken by Murphy [50] are shown in Figure 12. These effects, along with the overall magnitude of attenuation, are consistent with theoretical predictions. At low pressures, the attenuation is approximately an order of magnitude greater than that predicted by Biot theory.

The local flow mechanism predicts that absorption and dispersion will scale with the product of frequency and viscosity $(\omega \eta)$. By varying viscosity as well as frequency, experimentalists have been able to effectively broaden the frequency range available to any particular experimental technique. Many experimental results now exist showing attenuation varying with $\omega \eta$, with associated velocity dispersion $[25,40,50,75,79,101]$. Some of these observations may have been affected by fluid-flow to the boundaries of the sample, and therefore are not truly representative of a local-flow mechanism [26, 93]. However, some measurements are not affected by boundary flow. Figure 13 is an example from Jones and Nur [40] in which cylindrical samples were resonated in torsion. The samples were jacketed and under confining pressure. While the complete absorption peak has not been mapped, the frequency dependence is clear.

When pore fluid viscosity varies strongly with temperature, velocities can be significantly affected. At low temperature the viscosity is high and fluid cannot flow easily, so the measurement is on the high-frequency, high-velocity, unrelaxed side of the local-flow mechanism. As temperature increases, viscosity decreases, fluid flows more easily and velocity decreases as we move to the relaxed side of the absorption/dispersion mechanism. This effect is especially strong when the rock is saturated with viscous hydrocarbons. Figure 14 has data from Wang and Nur [87] showing velocities changing with temperature for air-, water- and oilsaturated sandstone.

The concept of relaxed vs unrelaxed velocities was explored in some detail by Murphy [52] and Winkler [97, 98]. Murphy showed that acoustic measurements made near $1 \mathrm{kHz}$ could be well described using Gassmann's equations, but ultrasonic data were better described using a model with unrelaxed pore fluid [61]. Winkler used ultrasonic velocity measurements on dry rock as input to Gassmann's equations to calculate the low-frequency velocity limit for saturated rock. He then noted that ultrasonic velocity measurements on saturated rock always exceeded this low-frequency limit in a manner consistent with dispersion caused by the local-flow mechanism. This showed that ultrasonic lab measurements were being affected by mechanisms operating at lower frequencies, and so were not entirely representative of velocities at seismic or sonic frequencies.

\section{FIELD APPLICATIONS}

Via the techiques of surface seismics, vertical seismic profiling, well-to-well seismics, and sonic well-logging, acoustics is the most widely used phenomenon for exploring and characterizing the earth's crust. The acoustic properties of interest are intrinsic velocities and attenuation, and impedance contrasts at structural interfaces.

Velocities are often used for lithology identification using correlations such as Pickett's crossplot (Figure 2). 


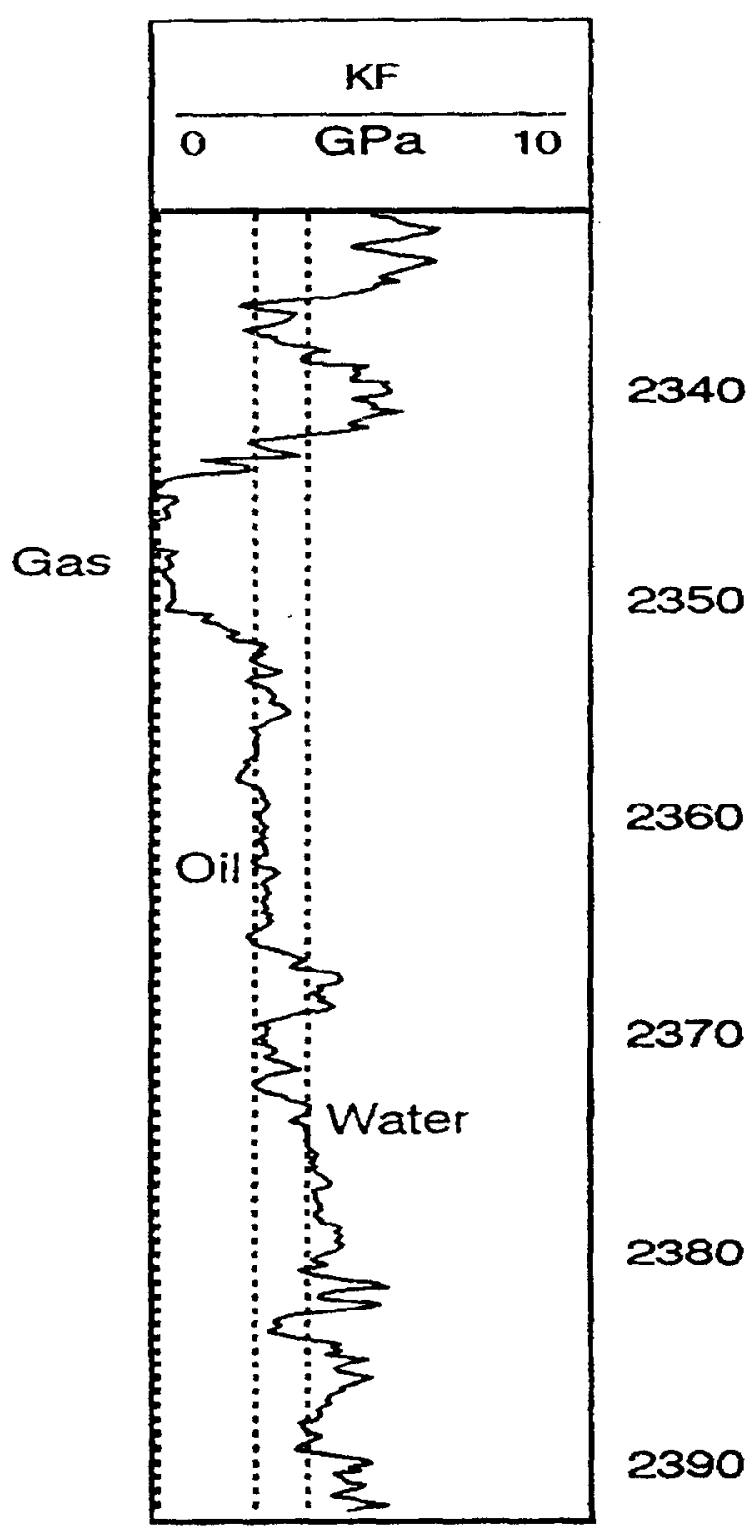

Fig. 15. Well-log from the Gulf of Mexico showing the bulk modulus of the pore fluid calculated by Murphy et al. [41]. Dotted lines are reference values for gas, oil, and water.

Additional information can be found by correlating velocities with other rock properties, such as density derived from nuclear well logs. When velocities are measured as continuous functions of depth in wellbores, the data can be integrated to yield the total acoustic traveltime to any depth, thereby providing depth calibration for surface reflection seismograms. The $\mathrm{V}_{\mathrm{P}} / \mathrm{V}_{\mathrm{S}}$ ratio is often used as a qualitative indicator of the presence of gas, since gas will reduce the compressional velocity, but not the shear velocity (Figure 7). Under suitable conditions of high porosity and small clay content, it is possible to calculate the pore fluid bulk modulus, thus distinguishing between gas, oil and water. Figure 15 from Murphy et al. [53] shows the results of such a calculation for an oil well in the Gulf of Mexico. The solid curve indicates the calculated bulk modulus of the pore fluid. The dashed reference lines labeled 'gas', 'oil' and 'water' represent the bulk moduli of those pore fluids. The presence of gas is indicated from 2343 to 2350 meters, oil from 2350 to 2365 meters and from 2368 to 2373 meters, and water elsewhere.

Attenuation data are not routinely used to determine rock properties because it is very difficult to get accurate measurements of attenuation, either from seismics or well-logs. It has long been known that the presence of gas will reduce compressional wave amplitudes, resulting in cycle-skipping on sonic logs. This is consistent with laboratory attenuation data (Figures 11 and 12). Attenuation is potentially more sensitive than velocity to the amount of gas in a rock.

Both velocity and attenuation have been used to estimate formation permeability from borehole Stoneley waves. High permeability decreases velocity and increases attenuation, consistent with theoretical models

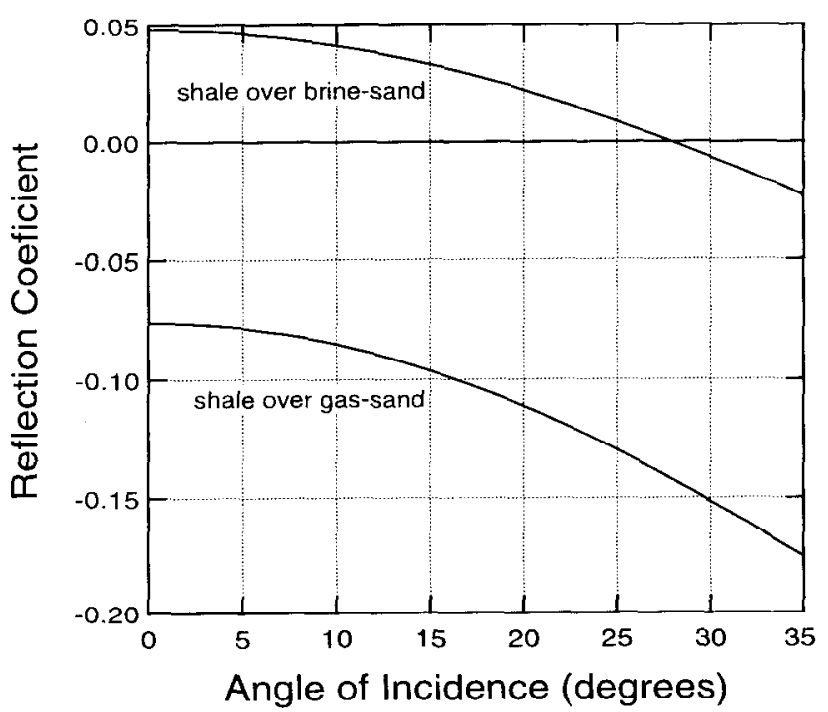

Fig. 16. Reflection coefficient vs angle of incidence for compressional waves at a shale/brine-sand interface, and a shale/gas-sand interface. Curves were calculated using Equation (5) and the rock properties in Table 2. These curves are the basis of AVO interpretation. 
WINKLER AND MURPHY 31

TABLE 2. AVO Velocity Model

\begin{tabular}{cccc}
\hline lithology & $\mathrm{V}_{\mathrm{P}}(\mathrm{m} / \mathrm{s})$ & $\mathrm{V}_{\mathrm{S}}(\mathrm{m} / \mathrm{s})$ & $\rho(\mathrm{g} / \mathrm{cc})$ \\
\hline shale & 2377 & 941 & 2.27 \\
brine sand & 2664 & 1253 & 2.23 \\
gas sand & 2249 & 1301 & 2.06 \\
\hline
\end{tabular}

and lab experiments (Figure 10). This technique is still gaining acceptance in the field, but has been successfully used under a wide variety of conditions $[13,17,33,62]$.

Use of rock acoustics for 'direct detection of hydrocarbon' has received considerable interest in recent years. In its simplest form, it has been observed that the low compressional velocity of gas reservoirs often produces a high impedance contrast with the overlying rock layer. This creates a high reflection coefficient between the layers and produces a so-called 'bright spot' (large amplitudes) on reflection seismograms. Bright spots can also be generated by oil reservoirs containing large volumes of dissolved gas which lowers the bulk modulus of the pore fluid $[2,20]$. In practice, many compressional wave bright spots are found to be caused by lithology contrasts rather than by pore fluid contrasts. Onc way to distinguish the two is to look for corresponding shear wave bright spots, which will be caused by lithology contrasts but not by hydrocarbons.

In the absence of shear seismic data, an alternative technique for identifying hydrocarbon-related bright spots is known as amplitude variation with offset, or AVO. This technique makes use of the fact that the reflection coefficient of a seismic wave varies with the angle of incidence at the reflector. At normal incidence, the reflection coefficient is a function of compressional wave velocities and densities, only. At non-normal incidence, the reflection coefficient is also a function of the contrast in shear wave velocities. The full equations for reflection coefficient vs incidence angle are very complicated [105], but with suitable approximations [1,73, 95], the following equation has simplified AVO interpretation-

$\mathrm{R}_{\mathrm{PP}}(\theta) \approx \mathrm{R}_{\mathrm{P}}+\left(\mathrm{R}_{\mathrm{P}}-2 \mathrm{R}_{\mathrm{S}}\right) \sin ^{2} \theta$

$R_{P P}$ is the reflection coefficient at angle $\theta, R_{P}$ and $R_{S}$ are the compressional and shear reflection coefficients at normal incidence. Figure 16 shows the results of applying Equation (5) to a shale overlying a brine-saturated sandstone, and overlying a gas-saturated sandstone. The input rock parameters are given in Table 2, taken from Swan [76].

For the shale over gas-sand, the reflection coefficient is slightly negative at normal incidence and becomes more negative with increasing angle. For the shale over brinesand, the reflection coefficient is positive at normal incidence and becomes negative with increasing angle. In principle, by modeling the variation of reflection coefficient with angle of incidence, it is possible to determine both $R_{P}$ and $R_{S}$. In practice, the technique is complicated by many effects such as attenuation, anisotropy, beam spreading, etc. Nevertheless, for several years AVO has been a subject of great interest in the seismic exploration community. A recent review volume by Castagna and Backus [14] is recommended.

\section{REFERENCES}

1. Aki, K. and P.G. Richards, Quantitative seismology: Theory and methods, W.H. Freeman and Co., 1980.

2. Batzle, M. and Z. Wang, Seismic properties of pore fluids, Geophysics, 57, 1396, 1992.

3. Berryman, J.G., Long-wavelength propagation in composite elastic media II. Ellipsoidal inclusions,
J.A.S.A., 68, 1820, 1980 .

4. Berryman, J.G., Mixture theories for rock properties, this volume.

5. Biot, M.A., Theory of propagation of elastic waves in a fluid saturated porous solid. I. Low-frequency range, J. Acoust. Soc. Am., 28, 168, 1956a.

6. Biot, M.A., Theory of propagation of elastic waves in a fluid saturated porous solid. II. High-frequency range, J. Acoust. Soc. Am., 28, 179, 1956b.

7. Biot, M.A., Mechanics of deformation and acoustic propagation in porous media, $J$. Appl.Phys., 33, 1482, 1962.

8. Birch, F., The velocity of compressional waves in rocks to 10 kilobars, Part 1, J. Geophys. Res., 
65, $1083,1960$.

9. Birch, F., The velocity of compressional waves in rocks to 10 kilobars, Part 2, J. Geophys. Res., 66, 2199, 1961.

10. Bonner, B.P., Shear wave birefringence in dilating granite, Geophys. Res. Lett., 1, 217, 1974.

11. Brace, W.F., B.W. Paulding, and C. Scholz, Dilatancy in the fracture of crystalline rocks, J. Geophys. Res., 71, 3939, 1966.

12. Bourbié, T., O. Coussy, and B. Zinszner, Acoustics of Porous Media, Institut Français du Pétrole Publications, Gulf Publishing Co., 1987.

13. Burns, D.R., Predicting relative and absolute variations of in-situ permeability from full-waveform acoustic logs, The Log Analyst, 32, 246, 1991.

14. Castagna, J.P. and M.M. Backus, Offset-dependent reflectivity Theory and practice of AVO analysis, Investigations in Geophysics Series, S.E.G., 1993.

15. Castagna, J.P., M.L. Batzle, and R.L. Eastwood, Relationships between compressional-wave and shear-wave velocities in clastic silicate rocks, Geophysics, 50, 571, 1984.

16. Chang, S.K., H. L. Liu, and D.L. Johnson, Low-frequency tube waves in permeable rocks, Geophysics 53, 519, 1988.

17. Cheng, C.H., Z. Jinzhong, and D.R. Burns, Effects of in-situ permeability on the propagation of Stoneley (tube) waves in a borehole, Geophysics, 52, 1279, 1987.

18. Cheng, C.H. and M.N. Toksöz, Inversion of seismic velocities for the pore aspect ratio spectrum of a rock, J. Geophys. Res., 84, 7533, 1979.

19. Christensen, N.I., Seismic Velocities, in CRC Handbook of Physical Properties of Rocks, Vol. II, edited by Robert S. Carmichael,
CRC Press, 1982.

20. Clark, V.A., The effect of oil under in-situ conditions on the seismic properties of rocks, Geophysics, 57 , $894,1992$.

21. Clark, V.A., B.R. Tittmann, and T.W. Spencer, Effect of volatiles on attenuation $\left(\mathrm{Q}^{-1}\right)$ and velocity in sedimentary rocks, $J$. Geophys. Res., 85, 5190, 1980.

22. Cook, N.G.W. and K. Hodgson, Some detailed stress-strain curves for rock, J. Geophys. Res., 70, 2883, 1965.

23. Crampin, S., Effective anisotropic elastic constants for wave propagation through cracked solids, Geophys. J. Roy. Ast. Soc., 76, 133, 1984.

24. Digby, P.J., The effective elastic moduli of porous granular rocks, $J$. Appl. Mech. ASME 28, 803, 1982.

25. Dunn, K.J., Acoustic attenuation in fluid-saturated porous cylinders at low frequencies, J. Acoust. Soc. Am., 79, 1709, 1986.

26. Dunn, K.J., Sample boundary effect in acoustic attenuation of fluidsaturated porous cylinders, $J$. Acoust. Soc. Am., 81, 1259, 1987.

27. Gardner, G.H.F., M.R.J. Wyllie, and D.M. Droschak, Effects of pressure and fluid saturation on the attenuation of elastic waves in sands, J. Pet. Tech., 189, 1964.

28. Gassmann, F., Uber die elastizitat poroser medien, Vier. der Natur. Gesellschaft, 96, 1, 1951.

29. Gordon, R.B. and L.A. Davis, Velocity and attenuation of seismic waves in imperfectly elastic rock, $J$. Geophys. Res., 73, 3917, 1968.

30. Gordon, R.B. and D. Rader, Imperfect elasticity of rock: Its influence on the velocity of stress waves, in Structure and Physical Properties of the Earth's Crust, Geophys. Monograph Series, v.14, edited by G. Heacock, 235, 1971.

31. Gregory, A.R., Aspects of rock physics from laboratory and log data that are important to seismic interpretation, Am. Assoc. Petr. Geol.Mem., 26, 15, 1977.

32. Han, D.-h., A. Nur, and D. Morgan, Effects of porosity and clay content on wave velocities in sandstones, Geophysics, 51, 2093, 1986.

33. Hornby, B.E. W.F. Murphy, H.L. Liu, and K. Hsu, Reservoir sonics: A North Sea case study, Geophysics, 57, 146, 1992.

34. Hudson, J.A., Wave speeds and attenuation of elastic waves in material containing cracks, Geophys. J. Roy. Ast. Soc., 64, 133, 1981.

35. Johnson, D.L., Recent developments in the acoustic properties of porous media, in Frontiers in Physical Acoustics, Course XCIII, North-Holland, Amsterdam, 1986.

36. Johnson, P.A., A. Migliori, and T.J. Shankland, Continuous wave phase detection for probing nonlinear elastic wave interactions in rocks, $J$. Geophys. Res., 89, 598, 1991.

37. Johnson, P.A., T.J. Shankland, R.J. O'Connell and J.N. Albright, Nonlinear generation of elastic waves in crystalline rock, $J$. Geophys. Res., 92, 3597, 1987.

38. Johnston, D.H. and M.N. Toksöz, Ultrasonic $P$ and $S$ wave attenuation in dry and saturated rocks under pressure, J. Geophys. Res., 85, 925, 1980.

39. Jones, L.E.A. and H. Wang, Ultrasonic velocities in Cretaceous shales from the Williston basin, Geophysics, 46, 288, 1981.

40. Jones, T. and A. Nur, Velocity and attenuation in sandstone at elevated temperatures and pressures, Geophys. Res. Lett., 10, 140, 1983.

41. King, M.S., Wave velocities in rocks as a function of changes in overburden pressure and pore fluid saturants, Geophysics, 31, 50, 1966.

42. Kowallis, B., L.E.A. Jones, and H. F. Wang, Velocity-porosity-clay 
content: Systematics of poorly consolidated sandstones, $J$. Geophys. Res., 89, 10355, 1984.

43. Kuster, G.T. and M.N. Toksöz, Velocity and attenuation of seismic waves in two-phase media: Part 1. Theoretical formulations, Geophysics, 39, 587, 1974.

44. Lo, Tien-when, K.B. Coyner, and M.N. Toksoz, Experimental determination of elastic anisotropy of Berea sandstone, Chicopee shale, and Chelmsford granite, Geophysics, 51, 164.

45. Lockner, D.A., J.B. Walsh, and J.D. Byerlee, Changes in seismic velocity and attenuation during deformation of granite, J. Geophys. Res., 82, 5374, 1977.

46. Mavko, G.M., Frictional attenuation: An inherent amplitude dependence, J. Geophys. Res., 80, 1444, 1979.

47. Mavko, G.M. and A. Nur, The effect of nonelliptical cracks on the compressibility of rocks, J. Geoph. Res., 83, 4769, 1978.

48. Mavko, G.M. and A. Nur, Wave attenuation in partially saturated rocks, Geophysics, 44, 161, 1979.

49. McKavanagh, B. and F.D. Stacey, Mechanical hysteresis in rocks at low strain amplitudes and seismic frequencies, Phys. Earth Planet. Int., 8, 246, 1974.

50. Murphy, W.F., Effects of partial water saturation on attenuation in Massilon sandstone and Vycor porous glass, J. Acoust. Soc. Am., $71,1458,1982$.

51. Murphy, W.F., Acoustic measures of partial gas saturation in tight sandstones, J. Geophys. Res., 89, 11,549, 1984.

52. Murphy, W.F., Sonic and ultrasonic velocities: Theory versus experiment, Geophys. Res. Lett., 12, 85,1985

53. Murphy, W., A. Reischer, and K. Hsu, Modulus decomposition of compressional and shear velocities in sand bodies, Geophysics, 58, 227, 1993.

54. Murphy, W.F., K.W. Winkler, and R.L. Kleinberg, Frame modulus reduction in sedimentary rocks: The effect of adsorption on grain contacts, Geophys. Res. Lett., 1, $805,1984$.

55. Murphy, W.F., K.W. Winkler, and R.L. Kleinberg, Acoustic relaxation in sedimentary rocks: Dependence on grain contacts and fluid saturation, Geophysics, 51, 757, 1986.

56. Nur, A., Effects of stress on velocity anisotropy in rocks with cracks, J. Geophys. Res., 76, 2022, 1971 .

57. Nur, A. and J.D. Byerlee, An exact effective stress law for elastic deformation of rock with fluids, $J$. Geophys. Res., 76, 6414, 1971.

58. Nur, A. and G. Simmons, Stressinduced velocily anisolropy in rock: An experimental study, J. Geophys. Res., 74, 6667, 1969.

59. Nur, A. and Z. Wang, Seismic and Acoustic Velocities in Reservoir Rocks: Vol. 1, Experimental Studies, S.E.G., Geophysics Reprint Series No. 10, 1989.

60. O'Connell, R.J. and B. Budiansky, Seismic velocities in dry and saturated cracked solids, $J$. Geophys. Res., 79, 5412, 1974.

61. O'Connell, R.J. and B. Budiansky, Viscoelastic properties of fluidsaturated cracked solids, $J$ Geophys. Res., 82, 5719, 1977.

62. Paillet, F.L., Qualitative and quantitative interpretation of fracture permcability using acoustic full-waveform logs, The $\mathrm{Log}$ Analyst, 32, 256, 1991.

63. Palmer, I.D. and M.L. Traviolia, Attenuation by squirt flow in undersaturated gas sands, Geophysics, 45 , 1780,1981

64. Peselnick, L. and W.F. Outerbridge, Internal friction in shear and sher modulus of Solenhofen limestone over a frequency range of $10^{7}$ cycles per second, J. Geoph. Res., 66, 581, 1961.

65. Pickett, G.R., Acoustic character logs and their applications in formation evaluation, J. Petr. Tech. $15,650,1963$.

66. Plona, T.J., Observations of a second bulk compressional wave in a porous medium at ultrasonic frequencies, Appl. Phys. Lett., 36, 259, 1980.

67. Podio, A.L., A.R. Gregory, and M. E. Gray, Dynamic properties of dry and water-saturated Green River shale under stress, Soc. Petr. Eng. $J ., 8,389,1968$.

68. Rai, C.S. and K.E. Hanson, Shearwave velocity anisotropy in sedimentary rocks: A laboratory study, Geophysics, 53, 800, 1988.

69. Rosenbaum, J.H., Synthetic microseismograms: logging in porous formations, Geophysics, 39, 14, 1974.

70. Savage, J, C., Comments on paper by R.B. Gordon and L.A. Davis, 'Velocity and attenuation of seismic waves in imperfectly elastic rock', J. Geophys. Res., 74, 726, 1969.

71. Sayers, C.M., Ultrasonic velocity dispersion in porous materials, $J$. Phys. D., 14, 413, 1981.

72. Sayers, C.M., J.G. van Munster and M.S. King, Stress-induced ultrasonic anisotropy in Berea sandstone, Int. J. Rock Mech, 27, 429.

73. Shuey, R.T., A simplification of the Zoeppritz equations, Geophysics, $50,609,1985$.

74. Simmons, G. and W.F. Brace, Comparison of static and dynamic measurements of compressibility of rocks, J. Geophys. Res., 70, 5649, 1965.

75. Spencer, J.W., Stress relaxations at low frequencies in fluid-saturated rocks: Attenuation and modulus dispersion, J. Geophys. Res., 86, 1803, 1981. 
76. Swan, H.W., Properties of direct AVO hydrocarbon indicators, in Offset-dependent reflectivity Theory and practice of $A V O$ analysis, Investigations in Gcophysics Series, ed. J.P. Castagna and M.M. Backus, S.E.G., 1993.

77. Thomsen, L., Weak elastic anisotropy, Geophysics, 51, 1954, 1986.

78. Tittmann, B.R., J.M. Curnow, and R.M. Housley, Internal friction quality factor $Q>3100$ achieved in lunar rock 70215,85, Proc. Lunar Sri. Conf. 6th, 3217, 1975.

79. Tittmann, B.R., H. Noadler, V.A. Clark, L.A. Ahlberg, and T.W. Spencer, Frequency dependence of seismic attenuation in saturated rocks, Geophys. Res. Lett., 8, 36, 1981.

80. Toksöz, M.N. and D.H. Johnston, Seismic Wave Attenuation, S.E.G., Geophysics Reprint Series No. 2, 1981.

81. Toksöz, M.N., D.H. Johnston, and A. Timur, Attenuation of seismic waves in dry and saturated rocks: I. Laboratory measurements, Geophysics, 44, 681, 1979.

82. Tosaya, C. and A. Nur, Effects of diagenesis and clays on compressional velocities in rocks, Geophys. Res. Lett., 9, , 1982.

83. Tutuncu, A.N. and M.M. Sharma, The influence of fluids on grain contact stiffness and frame moduli in sedimentary rocks, Geophysics, 57, 1571, 1992.

84. Vassiliou, M., C.A. Salvado, and B.R. Tittmann Seismic Attenuation, in CRC Handbook of Physical Properties of Rocks, Vol. III, edited by Robert S. Carmichael, CRC.
Press, 1982.

85. Vernik, L. and A. Nur, Ultrasonic velocity and anisotropy of hydrocarbon source rocks, Geophysics, 57, 727, 1992.

86. Walsh, J.B., The effect of cracks on the compressibility of rock, $J$. Geophys. Res., 70, 381, 1965.

87. Wang, Z. and A. Nur, Wave velocities in hydrocarbon-saturated rocks: Experimental results, Geophysics, 55, 723, 1990.

88. Wang, Z. and A. Nur, Seismic and Acoustic Velocities in Reservoir Rocks: Vol. 2, Theoretical and Model Studies, S.E.G., Geophysics Reprint Series No. 10, 1992.

89. Wang, Z., A. Nur, and M. Batzle, Acoustic velocities in petroleum oils, J. Petr. Tech., 42, 192, 1990.

90. Watt, J.P., G.F. Davies, and R.J. O'Connell, Elastic properties of composite materials, Rev. Geophys. Space Phys., 14, 541, 1976.

91. White, J.E., Seismic Waves: Radiation, Transmission and Attenuation, McGraw-Hill, N.Y., 302 pp., 1965.

92. White, J.E., Underground Sound: Application of seismic waves, Elsevier, Amsterdam, 253 pp., 1983.

93. White, J.E., Biot-Gardner theory of extensional waves in porous rods, Geophysics, 51, 742, 1986.

94. White, J.E., L. Martineau-Nicoletis, and C. Monash, Measured anisotropy in Pierre shale, Geophysical Prospecting, 31, 709, 1983.

95. Wiggins, R., G.S. Kenny, and C.D. McClure, A method for determining and displaying the shear-velocity reflectivities of a geologic formation, European Patent
Application 0113944, 1983.

96. Winkler, K.W., Frequency dependent ultrasonic properties of high-porosity sandstones, $J$. Geophys. Res., 88, 9493, 1983.

97. Winkler, K.W., Dispersion analysis of velocity and attenuation in Berea sandstone, J. Geophys. Res., 90, 183, 1985.

98. Winkler, K.W., Estimates of velocity dispersion between seismic and ultrasonic frequencies, Geophysics, 5I , 6793, 1986.

99. Winkler, K.W., H. Liu, and D. L. Johnson, Permeability and borehole Stoneley waves: Comparison between experiment and theory, Geophysics, 54 , 66, 1989.

100. Winkler, K and A. Nur, Pore fluids and seismic attenuation in rocks, Geophys. Res. Lett., 6, 1, 1979.

101. Winkler, K.W. and A. Nur, Seismic attenuation: Effects of pore fluids and frictional sliding, Geophysics, 47, 1, 1982.

102. Winkler, K., A. Nur, and $M$. Gladwin, Friction and seismic attenuation in rocks, Nature, 277, 528, 1979.

103. Wyllie, M.R.J., A.R. Gregory, and L.W. Gardner, Elastic wave velocities in heterogeneous and porous media, Geophysics, 21, 41, 1956.

104. Wyllie, M.R.J., A.R. Gregory, and G.H.F. Gardner, An experimental investigation of factors affecting elastic wave velocities in porous media, Geophysics, 23, 459, 1958.

105. Zoeppritz, K., On the reflection and propagation of seismic waves, Erdbebenwellen VIIIB, Gottinger Nachrichten, I, 66, 1919. 